\title{
Automated, high frequency, on-line dimethyl sulfide measurements in natural waters using a novel "microslug" gas-liquid segmented flow method with chemiluminescence detection
}

\author{
Geng Leng ${ }^{\text {a, * }}$, Chao-Feng Jin ${ }^{\text {a }}$, Thomas G. Bell ${ }^{\mathrm{b}}$, Simon J. Ussher ${ }^{\text {c, *** }}$, Paul J. Worsfold ${ }^{\mathrm{c}}$, \\ Wei-Yi Li ${ }^{\mathrm{d}}$ \\ ${ }^{a}$ School of Resources and Environment, University of Electronic Science and Technology of China, Chengdu, 611731, China \\ b Plymouth Marine Laboratory, Prospect Place, Plymouth, Devon, PL1 3DH, UK \\ ${ }^{\mathrm{c}}$ Biogeochemistry Research Centre, SoGEES, University of Plymouth, Plymouth, Devon, PL48AA, UK \\ ${ }^{\mathrm{d}}$ School of Science, Research Center for Advanced Computation, Xihua University, Chengdu, 610039, China
}

\section{A R T I C L E I N F O}

\section{Keywords:}

Dimethyl sulfide

Chemiluminescence

Natural waters

Segmented flow

Automated

On site analysis

\begin{abstract}
A B S T R A C T
Dimethyl sulfide (DMS) is the major biogenic volatile sulfur compound in surface seawater. Good quality DMS data with high temporal and spatial resolution are desirable for understanding reduced sulfur biogeochemistry. Here we present a fully automated and novel "microslug" gas-liquid segmented flow-chemiluminescence (MSSFCL) based method for the continuous in-situ measurement of DMS in natural waters. Samples were collected into a flow tank and DMS transferred from the aqueous phase to the gas phase using a vario-directional coiled flow, in which microvolume liquid and gas slugs were interspersed. The separated DMS was reacted with ozone in a reaction cell for CL detection. The analytical process was automated, with a sample throughput of $6.6 \mathrm{~h}^{-1}$. Using MSSF for DMS separation was more effective and easily integrated with CL detection compared with the commonly used bubbling approach. Key parameters of the proposed method were investigated. The linear range for the method was $0.05-500 \mathrm{nM}\left(\mathrm{R}^{2}=0.9984\right)$ and the limit of detection $(3 \times \mathrm{S} / \mathrm{N})$ was $0.015 \mathrm{nM}$, which is comparable to the commonly used gas chromatography (GC) method and sensitive enough for direct DMS measurement in typical aquatic environments. Reproducibility and recovery were assessed by spiking natural water samples (river, lake, reservoir and pond) with different concentrations of DMS (10, 20 and $50 \mathrm{nM}$ ), giving relative standard deviations (RSDs) $\leq 1.75 \%(n=5)$ and recoveries of $94.4-107.8 \%$. This fully automated system is reagent free, easy to assemble, simple to use, portable (weight $\sim 5.1 \mathrm{~kg}$ ) and can be left in the field for several hours of unattended operation. The instrumentation can provide high quality DMS data for natural waters with an environmentally relevant temporal resolution of $\sim 9 \mathrm{~min}$.
\end{abstract}

\section{Introduction}

Dimethyl sulfide (DMS) is a climatically active biogenic gas with an estimated annual global emission of $28-31 \mathrm{Tg} \mathrm{S}^{-1}$. Natural emissions account for approximately $78 \%$ of the total natural reduced sulfur global flux to the atmosphere [1,2] by transfer from seawater, freshwater [3,4], soil $[5,6]$ and plants [7]. After emission to the atmosphere, DMS can be oxidized to $\mathrm{SO}_{2}$, which is a precursor of sulfate aerosol particles that may act as cloud condensation nuclei (CCN) [8]. CCN are important for climate because they affect the radiative properties of the atmosphere and clouds by scattering solar radiation and influencing cloud microphysics and albedo $[9,10]$.

DMS is volatile in natural waters and can be oxidized [11] and converted to other sulfur compounds by microorganisms [12]. The transient nature of DMS means that in-situ analysis is essential. Currently, the most commonly used method for DMS quantification is purge and trap gas chromatography (PT-GC) $[13,14]$ coupled with flame photometric [15] or mass spectrometric detection [16]. These GC based techniques involve bulky instrumentation, require controlled laboratory settings and have a relatively low sample throughput, which restricts the

\footnotetext{
* Corresponding author.

$* *$ Corresponding author.

E-mail addresses: gengleng@uestc.edu.cn (G. Leng), tbe@pml.ac.uk (T.G. Bell), simon.ussher@plymouth.ac.uk (S.J. Ussher).
} 
ability to make near-continuous measurements $[17,18]$. Techniques such as membrane inlet mass spectrometry (MIMS) [19], equilibrator inlet proton transfer reaction mass spectrometry (EI-PTRMS) [20-22] and atmospheric pressure chemical ionization-mass spectrometry (AP-CIMS) [23,24] have become attractive for real-time DMS analysis on research vessels. However, these devices are relatively heavy, fragile, expensive and labor intensive to deploy on a ship.

An alternative strategy for measuring DMS is using gas phase chemiluminescence (CL) based on the chain reaction of DMS with ozone to form the sulfur monoxide radical (SO.), which then reacts with ozone to produce light with a wavelength maximum $\left(\lambda_{\max }\right)$ at $370 \mathrm{~nm}[25,26]$. The reaction is summarized in eq. (1) and eq. (2).

DMS $+\frac{1}{3} \mathrm{O}_{3} \quad \begin{gathered}\text { chain } \\ \text { reactions }\end{gathered} \mathrm{SO}$.

$\mathrm{SO} \cdot+\mathrm{O}_{3} \rightarrow \mathrm{SO}_{2}^{*}+\mathrm{O}_{2} \rightarrow \mathrm{SO}_{2}+h v$

Green et al. [27] adapted a laboratory-based gas phase CL instrument for real-time determination of DMS in marine samples. Air was bubbled through the sample to transfer DMS from the aqueous phase to the gas phase. DMS and ozone mixed in a reaction chamber and the CL signal was recorded using a photomultiplier tube. A short-pass optical filter was used to reduce CL interference from other gases but this also reduced the DMS signal by $89.7 \%$ and interference from methanethiol could not be eliminated. Toda's group have pioneered the development of simple methods for the in-situ measurement of DMS in seawater using gas phase CL in both sequential and batchwise approaches [28-31]. DMS was vaporized and introduced into the CL reaction cell by a physical shot or bubbling, while interferences from other gases were removed either by adding a heavy metal agent to the sample or by using a soda lime column.

Here we present a fully automated microslug segmented flowchemiluminescence (MSSF-CL) system for the continuous measurement of DMS in natural waters. With the proposed MSSF approach, nanomolar concentrations of DMS can be effectively transferred from the aqueous phase to the gas phase for CL detection. The whole analytical procedure, including in-situ sampling, separation, CL quantification and rinsing, was automated. This analytical system is easy to setup and operate, can be remotely operated and is light and portable (weight $\sim 5.1 \mathrm{~kg}$ ) and avoids the necessity of using any reagents other than oxygen. The performance of the automated system was demonstrated by several hours of unattended, high temporal resolution DMS measurement in the field.

\section{Experimental section}

\subsection{Reagents}

A 1.0 mM DMS stock solution was prepared by diluting a DMS certified standard (o2si, CA, USA) with methanol. The DMS stock solution was stored in a $20 \mathrm{~mL}$ glass vial with an aluminum screw top cap and airtight silicon septum at $-10{ }^{\circ} \mathrm{C}$ in the dark to minimize evaporation. A 1.0 $\mu \mathrm{M}$ DMS working solution was prepared daily by dilution of the stock solution with Milli-Q water. A 10 ppmv DMS gas standard cylinder (in nitrogen $\left(\mathrm{N}_{2}\right)$, Sichuan Zhongce Biaowu Technology, Chengdu, China) was used for calibration. The dilution of the DMS gas standard was achieved using a compressed $\mathrm{N}_{2}$ cylinder $(\geq 99.999 \%$ purity, Sichuan Qiao Yuan Gas, Chengdu, China). Compressed $\mathrm{N}_{2}$ was also used as the gas source in the segmented flow line and the carrier gas to introduce DMS into the CL cell. An oxygen $\left(\mathrm{O}_{2}\right)$ cylinder $(\geq 99.99 \%$ purity, Sichuan Qiao Yuan Gas, Chengdu, China) was used as the source gas for ozone generation.

\subsection{Apparatus}

A peristaltic pump (YZ-15 pump head, BT50S driver, Lead Fluid Technology Co., Ltd., Baoding, China) was used for water sampling. A set of three-way solenoid valves (VAS101, Ristron, Jiashan, China) and a 9600-step syringe pump (PVS-100, Ristron, Jiashan, China) equipped with a $10 \mathrm{~mL}$ syringe (Hamilton, CA, USA) were used for handling the aqueous samples and water. Ozone was generated by an ozone generator (M1000, Tonglin Technology, Beijing, China) with a maximum output of $1 \mathrm{~g} \mathrm{~h}^{-1}$. The ozone output was adjustable by changing the generator working power. Mass flow controllers (S48 300/HMT, Horiba Metron Instruments, Beijing, China) were used to regulate gas flow rates in the analytical system. A glass made gas-liquid separator (Sichuan Shubo, Chengdu, China) was used for phase separation after the MSSF and the separated gas sample was injected into the CL detection system using an electrically actuated 6-port injection valve (Valco Instruments, Houston, USA) and a PTFE holding coil $(2.5 \mathrm{~m} \times 3.175 \mathrm{~mm}$ i. d. $)$. The CL detection system comprised a CL reaction cell $(40 \mathrm{~mm} \times 25 \mathrm{~mm} \mathrm{i.} \mathrm{d.)}$ and a photomultiplier tube (PMT; R3550P, Hamamatsu Photonics, Japan). The reaction cell was made of stainless steel and the inside wall was chromium-plated to enhance light reflection. The PMT was located in an aluminum housing ( $95 \mathrm{~mm} \times 55 \mathrm{~mm}$ i. d.) sealed from external light sources. An optical convex lens $(\mathrm{d}=25 \mathrm{~mm}, \mathrm{f}=25.4 \mathrm{~mm})$ was placed between the CL cell and the PMT to focus the light. The CL signal was recorded in photon counting mode using a multifunctional photon signal analyzer (Novaphoton Technology, Chengdu, China), with an integrated high voltage DC power supply for the PMT. The output from the detector was recorded in photon counting units (p.c.u.) and all CL intensity data are reported as the integral of p.c.u. over time. A schematic diagram of the CL system is shown in Fig. S- 1 .

\subsection{Analytical procedures}

A schematic of the MSSF-CL instrument for the determination of DMS is shown in Fig. 1. Samples were collected by placing tubing with a 16 mesh $(1.0 \mathrm{~mm})$ nylon net over the opening below the water surface. With a peristaltic pump (PP) and a set of polyethersulfone (PES) filters (FT1, $50 \mathrm{~mm} \times 100 \mu \mathrm{m}$; FT2, $50 \mathrm{~mm} \times 10 \mu \mathrm{m}$; FT3, $50 \mathrm{~mm} \times 0.8 \mu \mathrm{m}$ ), samples were continuously collected into a $50 \mathrm{~mL}$ sample flow tank at $200 \mathrm{~mL} \mathrm{~min}{ }^{-1}$. The sample in the flow tank was either discharged to waste or held ready for analysis. $10 \mathrm{~mL}$ of sample was pulled into the syringe (SY) by the syringe pump (SP) at $150 \mathrm{~mL} \mathrm{~min}^{-1}$ and subsequently expelled to the T-junction (PP, $0.3 \mathrm{~mm}$ i. d.) at $2.0 \mathrm{~mL} \mathrm{~min}^{-1}$. Compressed $\mathrm{N}_{2}$ regulated by the mass flow controller (MFC) was delivered to the T-junction at a flow rate of $4.0 \mathrm{~mL} \mathrm{~min}{ }^{-1}$. Segmented gas-liquid microslugs formed as the gas and water mixed at the $\mathrm{T}$ junction and these microslugs entered a vario-directional flow coil (PP, $20 \mathrm{~m} \times 1 \mathrm{~mm}$ i. d., see Fig. 3 (c)). DMS transferred from the aqueous phase into the gas phase within the flow coil. The gas sample was separated in the gas-liquid separator and then passed through a soda lime-packed column that dried the gas stream and eliminated any potential signal interferences. Sample gas was collected in a holding coil (PTFE, $2.5 \mathrm{~m} \times 3.175 \mathrm{~mm}$ i. d.) and a 6-port injection valve was switched periodically to pump the sample into the CL reaction cell at $400 \mathrm{~mL} \mathrm{~min}^{-1}$. Ozone was delivered continuously into the CL reaction cell at $200 \mathrm{~mL} \mathrm{~min}^{-1}$. DMS reacted with ozone in the cell to produce a CL signal, which was detected and amplified by the PMT and recorded by the photon signal analyzer in photon counting mode. Waste air was passed through an activated carbon column before discharge to the ambient environment. The system was rinsed three times with $10 \mathrm{~mL}$ of water, which was aspired into the syringe and expelled towards the MSSF-CL system. The flow rate for both water and gas in the rinsing line

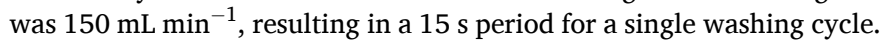
The CL reaction cell and its connecting tubing for DMS introduction were shielded from light by wrapping them with aluminum foil. A photograph of the MSSF-CL analysis system is provided in Fig. S-2. 


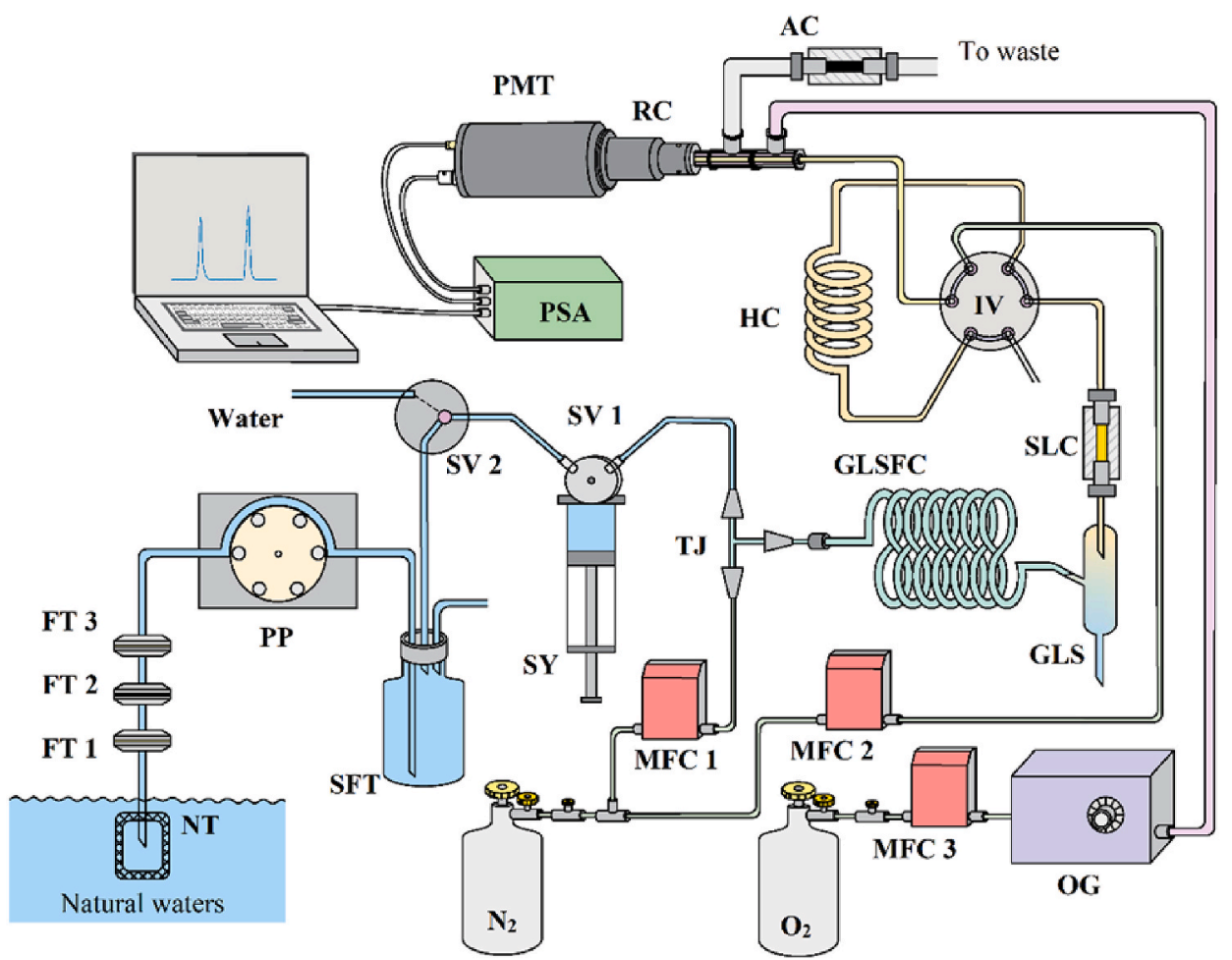

Fig. 1. A schematic diagram of the proposed MSSF-CL instrument for the determination of DMS. NT, nylon net; FT 1-3, filter; PP, peristaltic pump; SV 1 and 2, three-way solenoid valves; SFT, sample flow tank; SY, syringe; TJ, T-junction; MFC 1-3, mass flow controllers; OG, ozone generator; GLSFC, gas-liquid segmented flow coil; GLS, gas-liquid separator; IV, 6-port injection valve; HC, holding coil; SLC, soda lime column; RC, chemiluminescence reaction cell; PMT, photomultiplier tube; PSA, photon signal analyzer; AC, active carbon column.
Windows based, self-programmed software written in $\mathrm{C}++$ was used to control the syringe pump, MFCs, solenoid valves and the injection valve. Details of the operation of these control units are shown in Table S-3.

\section{Results and discussion}

\subsection{Flow and mixing regime}

DMS must be effectively transferred from the aqueous phase into the gas phase prior to its introduction into the CL cell. In a coiled, gas-liquid segmented flow, centrifugal forces create a secondary flow and the liquid and gas slugs create two counter rotating vortices that cause asymmetrical micro-recirculation towards the main flow direction (see Fig. 2), resulting in increased mass transfer between the two phases [32]. We used a $20 \mathrm{nM}$ DMS solution to compare our gas-liquid segmented flow system with the bubbling or 'purging' approach that is often used to transfer DMS from liquid to gas phase (Fig. 3). DMS transfer from a $10 \mathrm{~mL}$ sample volume was 1.67 -fold more effective using the gas-liquid segmented flow approach because the microslugs are a more stable and homogeneous gas-liquid dispersion system. DMS transfer is enhanced in the segmented flow compared with the bubbling approach because the surface area to volume ratio (gas-liquid contact area) is greater, the mass transfer diffusion distance is shorter and there is intense relative motion between the two phases [32-34]. Moreover, bubble films can form when air bubbles are introduced into the sample at higher speed, which could result in an inferior and unstable CL signal.

We also compared vario-directional and unidirectional segmented flow. Vario-directional flow was achieved by entwining tubing on two glass rods in alternating clockwise and counterclockwise directions. The vario-directional flow gave a $\sim 10 \%$ higher response than the unidirectional flow (Fig. 3). This may be because the rate of recirculation in liquid and gas slugs when the flow enters a coil is greater at the inner wall than at the outer wall. As the slugs move along the vario-directional segmented flow channel, the asymmetrical recirculation switches periodically (see Fig. 2), thereby increasing the relative motion between the two phases, resulting in enhanced DMS mass transfer. Note that the degree of this relative motion mainly depended on the size of the liquid and gas slugs and the curvature radius [33,35].

The geometry of the tubing (curve radius, $R$, and internal diameter, $D$ ) in the gas-liquid segmented flow coil significantly influences DMS mass transfer from the sample microslugs (Fig. 3). A tighter coil radius enhances asymmetrical recirculation in the microslugs, whilst

Main flow dircction

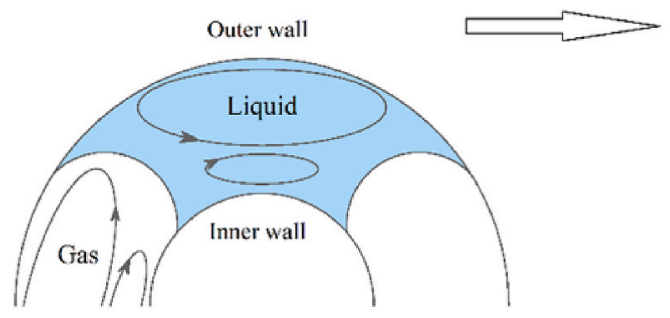

(a)

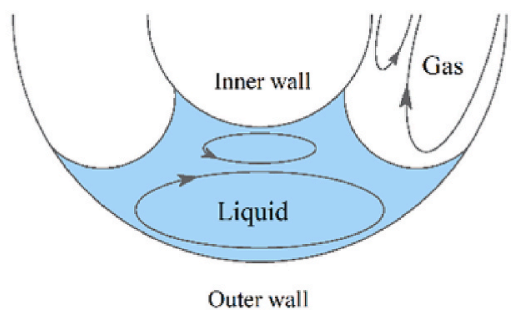

(b)

Fig. 2. Effect of gas and liquid slugs moving through a coiled tube in (a) clockwise and (b) counterclockwise directions. 


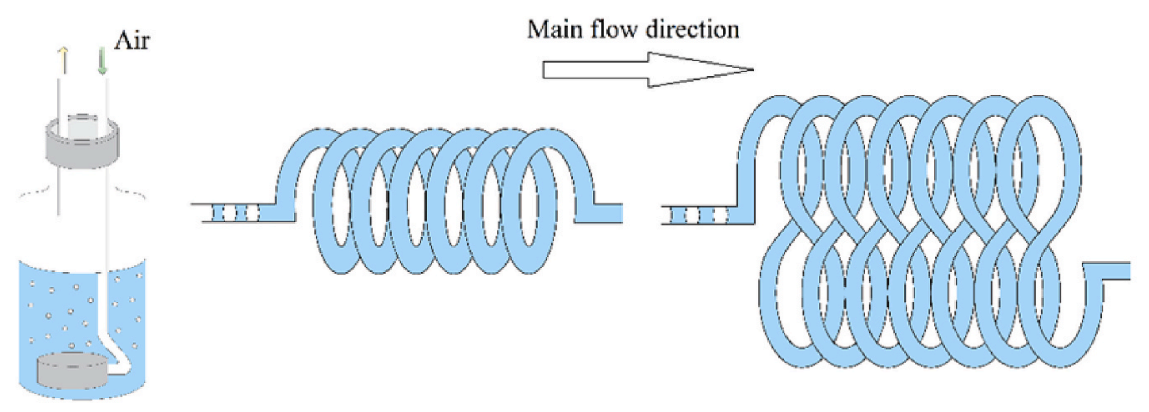

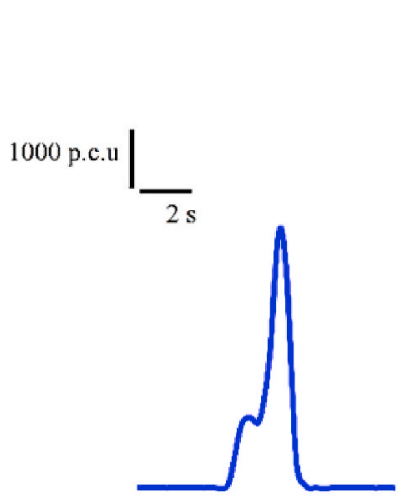

(a)

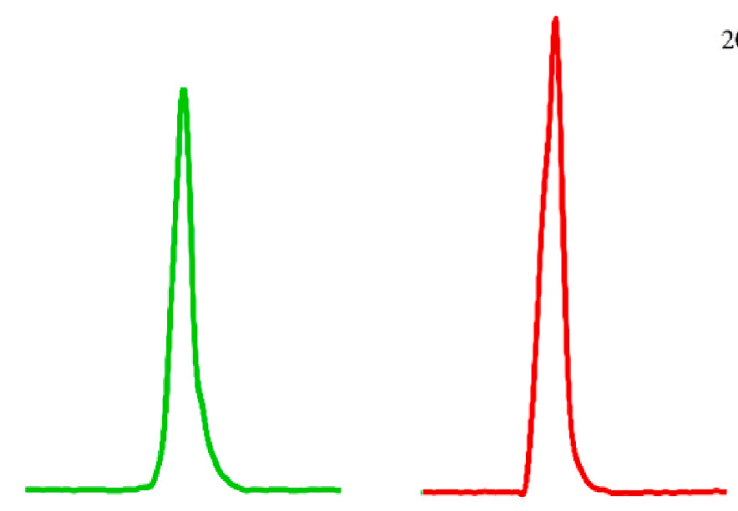

(b)
20 nM DMS

(c)

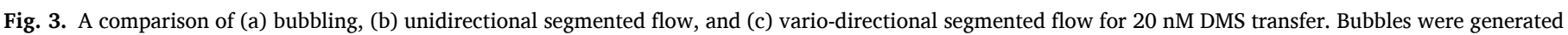

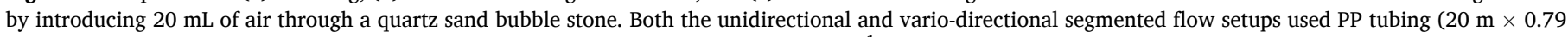
$\mathrm{mm}$ i. d.) with $1 \mathrm{~cm}$ curve radius. Liquid and gas were delivered at 2.0 and $4.0 \mathrm{~mL} \mathrm{~min}{ }^{-1}$ respectively. Peak height recorded as photon counting units (p.c.u.).

increasing the internal diameter increases the contact area between the gas and liquid phases and the retention time of the microslugs in the flow coil, all of which enhance the CL intensity (see Fig. 4). However, we did not observe any significant enhancement in CL intensity when $D>1 \mathrm{~mm}$ and $R<1 \mathrm{~cm}$ were applied, suggesting that complete mass transfer was achieved at $D=1.0 \mathrm{~mm}$ and $R=1.0 \mathrm{~cm}$ and hence these values were used for all subsequent experiments. Flow tubing with larger internal diameter resulted in longer residence times (quantitative data for these experiments are provided in Table S-4). The length of the segmented

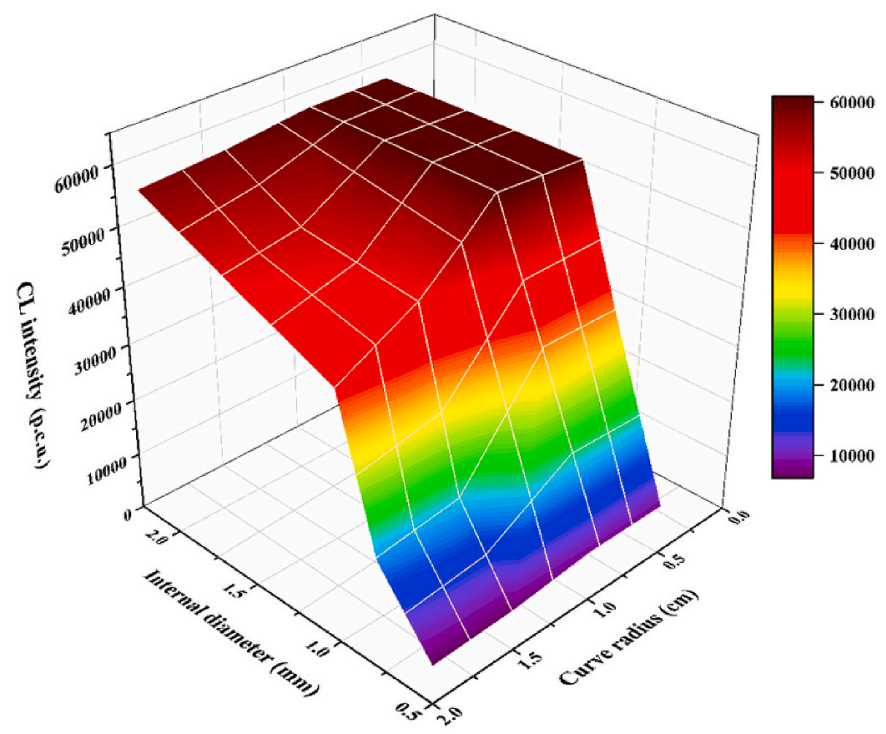

Fig. 4. Effect of segmented flow tubing curve radius and internal diameter on $20 \mathrm{nM}$ DMS mass transfer in MSSF-CL method (coil tubing length $=20 \mathrm{~m}$; liquid flow rate $=2 \mathrm{~mL} \mathrm{~min}^{-1}$; gas flow rate $=4 \mathrm{~mL} \mathrm{~min}^{-1}$ ). flow coil affected the residence time of the microslugs, which may have a positive effect on the efficiency of DMS mass transfer. We compared different lengths of tubing $(5,10,20$ and $30 \mathrm{~m})$. The efficiency of DMS mass transfer increased as the tubing length increased from 5 to $20 \mathrm{~m}$, and there was no difference between 20 and $30 \mathrm{~m}$, suggesting that complete DMS mass transfer had occurred.

\subsection{T-junction geometry and gas/liquid flow rates}

Microslug formation in the proposed method was achieved using a Tjunction and the size of the microslugs in the segmented flow were influenced by the dimensions of the T-junction [36], the flow rates of the fluid [37] and the relative viscosity of the two phases [38]. The effect of the T-junction inlet width and the gas flow rate were studied while keeping the sample flow rate constant at $2.0 \mathrm{~mL} \mathrm{~min}^{-1}$ (Fig. 5). By increasing the gas flow rate, the gas and liquid drop volume ratio $\left(\mathrm{V}_{\mathrm{gd}} / \mathrm{V}_{\mathrm{ld}}\right)$ also increased, generating smaller liquid microslugs in the segmented flow. The total gas-liquid contact area was increased and DMS mass transferring consequently enhanced, resulting in a higher DMS signal. However, at higher gas flow rates $\left(>4.0-6.0 \mathrm{~mL} \mathrm{~min}^{-1}\right)$, the DMS signal levelled off or decreased (Fig. 5). This may be because a higher flow rate leads to the use of a larger volume of gas, which is likely to dilute the DMS and ozone concentrations in the CL reaction cell. Moreover, the retention time of the microslugs in the segmented flow may be decreased at higher flows, resulting in reduction of DMS mass transfer efficiency. Different T-junction inlet internal diameters (0.3, 0.5 and $1.0 \mathrm{~mm}$ ) were also compared. Smaller drops were generated when using a narrower inlet at the same flow rate, resulting in a higher DMS signal (Fig. 5). It was not possible to source T-junctions with a lower i. d., but the recovery for DMS measurements using the $0.3 \mathrm{~mm}$ inlet i. $d$. T-junction at a gas flow rate of $4.0 \mathrm{~mL} \mathrm{~min}^{-1}$ was $97.1 \%(\mathrm{n}=3)$, indicating complete DMS mass transfer. Consequently, the optimum conditions for generating the segmented microslugs were gas and sample flow rates of 4.0 and $2.0 \mathrm{~mL} \mathrm{~min}^{-1}$ respectively through a $0.3 \mathrm{~mm}$ i. d. 


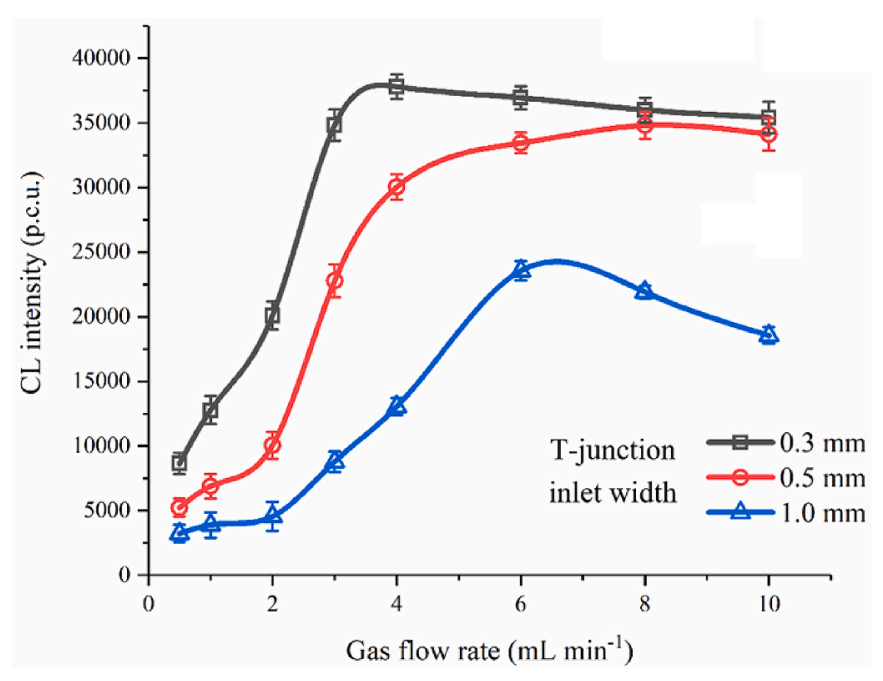

Fig. 5. Effects on CL intensity due to T-junction inlet width and gas flow rate through the coil. The segmented flow setup used PP tubing $(20 \mathrm{~m} \times 1.0 \mathrm{~mm}$ i. d.) with a $1 \mathrm{~cm}$ curve radius and vario-directional flow. Error bars represent \pm 1 SD of triplicate measurements.

\section{T-junction.}

\subsection{Effect of salinity on CL detection}

It is important to be able to apply the MSSF-CL method to saline matrices in order to study the biogeochemistry of DMS in natural waters. However, salt is often added to aqueous samples to enhance the mass transfer of volatile compounds into the headspace by lowering their partition coefficient [6,39]. A $20 \mathrm{nM}$ DMS sample was spiked with varying concentrations of $\mathrm{NaCl}$ (to give sample salinities, expressed as $\mathrm{m} / \mathrm{v} \mathrm{NaCl}$, in the range $0-5 \%, \mathrm{~m} / \mathrm{v}$ ), and subjected to analysis by MSSF-CL. As shown in Table 1 , no significant signal variation was observed, i.e. all results were within the mean \pm 2 standard deviations $(58,800 \pm 650)$. Further evidence of the suitability of the method for analyzing saline samples is shown in Fig. 6, which compares calibration graphs for DMS (0-100 nM) in $0 \%$ and 3.5\% NaCl. There is no significant difference between the calculated and tabulated $\mathrm{t}$ values $\left(\mathrm{t}_{\mathrm{calc}}=4.956\right.$; $t_{\mathrm{tab}}=9.605$ respectively) between the slopes of the two calibrations.

\subsection{Effect of ozone flow rate and concentration on CL detection}

DMS and ozone were introduced into the CL cell through concentric tubes and the CL reaction occurred in the center of the reaction cell. CL intensity depends on maximizing the emission within the cell window. We therefore investigated the effect of different ozone concentrations on $\mathrm{CL}$ intensity by adjusting the $\mathrm{O}_{2}$ input flow rate and the power supplied to the ozone generator. Lowering the $\mathrm{O}_{2}$ flow rate enhanced the $\mathrm{CL}$

Table 1

Effect of sample salinity (as $\mathrm{NaCl}$ ) for $20 \mathrm{nM}$ DMS measurement by MSSF-CL.

\begin{tabular}{lll}
\hline Sample salinity (\%, m/v) & CL intensity (p.c.u.) & $\begin{array}{l}\text { RSD (n = 3) } \\
(\%)\end{array}$ \\
\hline 0.0 & 59,200 & 1.3 \\
0.5 & 58,500 & 1.7 \\
1.0 & 58,700 & 1.6 \\
1.5 & 58,800 & 1.6 \\
2.0 & 59,000 & 1.5 \\
2.5 & 58,200 & 1.6 \\
3.0 & 58,500 & 1.7 \\
3.5 & 59,200 & 1.5 \\
4.0 & 58,800 & 1.4 \\
4.5 & 59,000 & 1.3 \\
5.0 & 58,600 & 1.7 \\
\hline
\end{tabular}

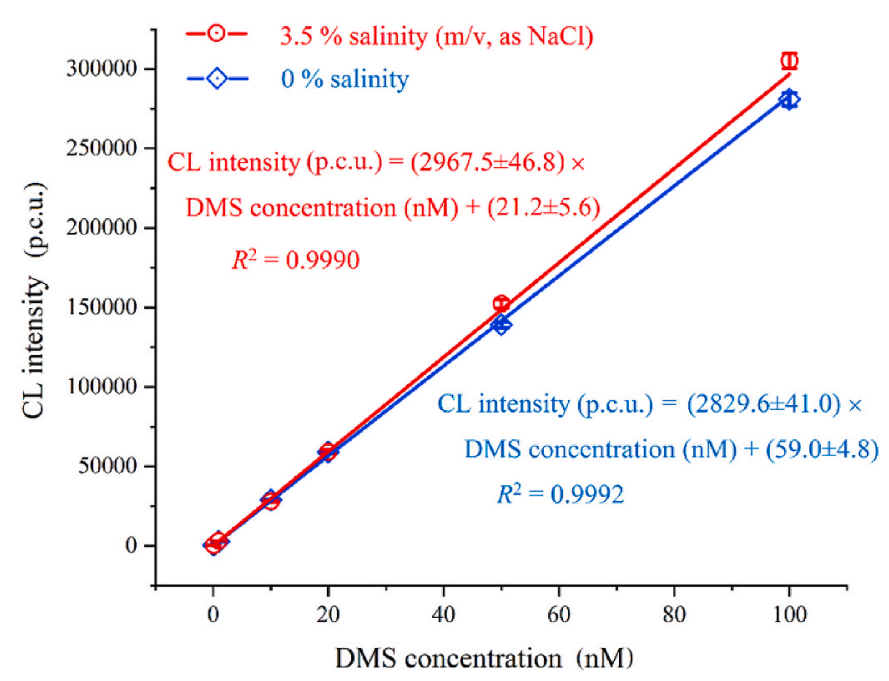

Fig. 6. Calibration graphs for DMS measurement by the proposed MSSF-CL method for samples with 0 and $3.5 \%(\mathrm{~m} / \mathrm{v}$, as $\mathrm{NaCl})$ salinity. Error bars represent \pm 1 SD of triplicate measurements.

signal due to a longer residence time in the cell and more efficient ozone production in the generator. If the $\mathrm{O}_{2}$ flow rate dropped too low however, excess ozone was produced, resulting in a quenching of the CL signal. The effect of ozone flow rate and concentration on the DMS signal is shown in Table S-5, with a maximum CL intensity achieved when ozone was delivered into the reaction cell at $200 \mathrm{~mL} \mathrm{~min}^{-1}$ with a concentration of $6550 \mathrm{ppmv}$ (with the ozone generator working at $40 \%$ of its maximum output). Air was not used as an ozone source in this study due to unstable ozone production (RSD $\geq 10.2 \%, n=5$ ) at low flow rates $\left(\leq 250 \mathrm{~mL} \mathrm{~min}^{-1}\right)$. It should be noted that the optimum flow rates of both ozone and the carrier gas, as well as the ozone concentration, vary over a relatively wide range when different shapes and sizes of reaction cell are used [27-31].

\subsection{Interference study}

Certain compounds positively interfere with the DMS measurement by reacting with ozone to produce a CL signal [27,29-31,40-42] and the effect of these compounds at three concentrations was therefore investigated using the relative CL intensity, which was defined as the ratio of the CL intensity of the potential interferent with DMS and the CL intensity of DMS alone. The results are shown in Table $2.100 \mathrm{nM}$ of ethene or propene produces a CL signal equivalent to $\sim 3.3-3.9 \mathrm{nM}$ DMS. Ethene and propene are not found in most natural waters and therefore interferences would be negligible [43]. $100 \mathrm{nM}$ Dimethyl disulfide (DMDS) produces a CL signal equivalent to $2 \mathrm{nM}$ DMS. The concentration of DMDS in freshwaters is typically no more than $17 \%$ of the DMS

Table 2

Relative CL intensity (\%CL $=\mathrm{CL}_{\text {spiked }} / \mathrm{CL}_{\mathrm{DMS}}$ only $)$ due to potential interference to the MSSF-CL signal from other compounds. Compounds were spiked into a 10 $\mathrm{nM}$ aqueous DMS aqueous sample.

\begin{tabular}{llcc}
\hline Compound & \multicolumn{2}{l}{ Relative CL intensity (\%) } \\
\cline { 2 - 4 } & $1 \mathrm{nM}$ & $10 \mathrm{nM}$ & $100 \mathrm{nM}$ \\
\hline DMS & 100.0 & & \\
Isoprene & 100.1 & 100.7 & 109.0 \\
Ethene & 100.3 & 104.1 & 132.7 \\
Propene & 100.3 & 103.4 & 139.1 \\
Hydrogen sulfide & 100.0 & 100.1 & 100.8 \\
Methyl mercaptan & 100.4 & 100.4 & 101.2 \\
Carbon disulfide & 100.1 & 101.2 & 110.0 \\
Dimethyl disulfide & 100.5 & 102.7 & 120.0 \\
Carbonyl sulfide & 100.1 & 100.2 & 100.4 \\
\hline
\end{tabular}


concentration [44,45], suggesting a maximum interference of $\sim 1 \%$. Methyl mercaptan $\left(\mathrm{CH}_{3} \mathrm{SH}\right)$ is a biologically generated sulfur compound found in natural waters [46] and is more volatile than DMS (Henry's law constant of $0.39 \mathrm{M} \mathrm{atm}^{-1}$ and $0.56 \mathrm{M} \mathrm{atm}^{-1}$ for $\mathrm{CH}_{3} \mathrm{SH}$ and DMS respectively). Previous CL work has reported a comparable (or higher) CL signal relative to DMS [13,29-31,47]. A column packed with soda lime was introduced between the gas-liquid separator and the holding cell. The column eliminated the $\mathrm{CH}_{3} \mathrm{SH}$ interference, dried the sample gas and had no detectable impact on the DMS signal.

\subsection{Analytical figures of merit}

Under optimum conditions, the linearity of the proposed MSSF-CL method for DMS determination was in the range 0.05-500 $\mathrm{nM}\left(\mathrm{R}^{2}=\right.$ 0.9984). The limit of detection (LOD) calculated from three times the signal-to-noise ratio was $0.015 \mathrm{nM}$. The reproducibility and recovery of the MSSF-CL method was investigated by analyzing four natural water matrices (river, lake, reservoir and pond; see Fig. 7 caption for further matrix details) spiked with different concentrations of DMS (10, 20 and $50 \mathrm{nM}$ ). The RSDs were $\leq 1.8 \%$ ( $\mathrm{n}=5$ for each set of measurements) and recoveries were $94.4-107.8 \%$, indicating acceptable precision and accuracy for the analysis of natural water samples. The complete analytical cycle (including rinsing) took $548 \mathrm{~s}$, which provided a sample throughput of $\sim 6.6 \mathrm{~h}^{-1}$. A comparison of the MSSF-CL method with purge and trap gas chromatography with mass spectrometric detection (PT-GC-MS) demonstrated satisfactory agreement with minimal apparent bias (slope $=1.042 \pm 0.018$, intercept $=-0.159 \pm 0.096, \mathrm{R}^{2}=$ 0.9947; see Fig. 7), which shows that the proposed method is robust and can perform well for a broad variety of aqueous sample matrices. Analytical conditions for the PT-GC-MS method are described in Method S-6 and the figures of merit are given in Table S-7.

\subsection{Field analysis of freshwater samples}

The suitability of the proposed method for field deployment was

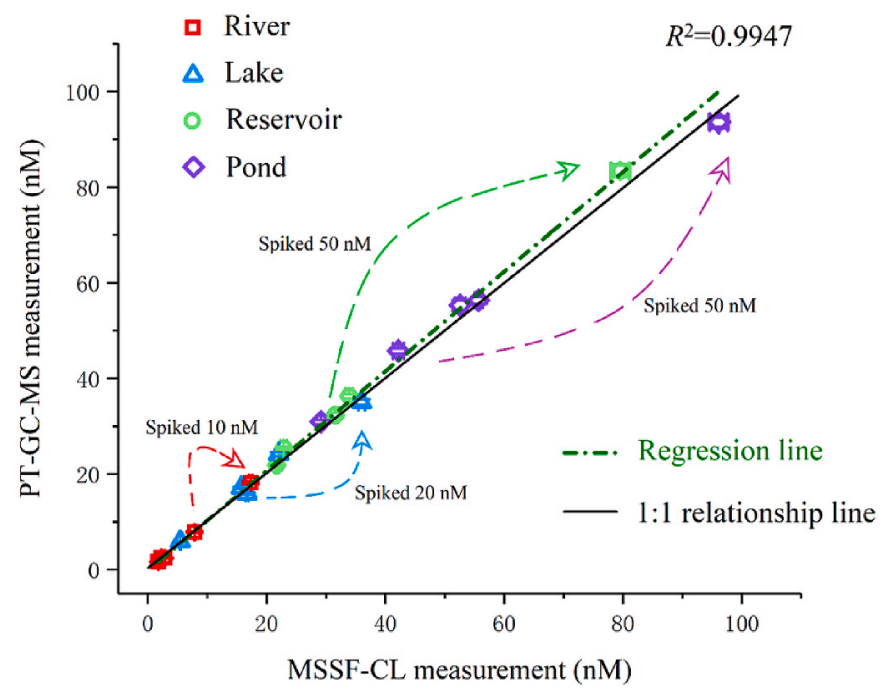

Fig. 7. Comparison of DMS measurement in different freshwater samples by MSSF-CL and PT-GC-MS. Regression equation (with 95\% confidence intervals) follows PT-GC-MS measurement $(\mathrm{nM})=1.042( \pm 0.018)$ x MSSF-CL measurement $(\mathrm{nM})-0.159( \pm 0.096)$. Lake and pond samples were collected from East Lake (University of Electronic Science and Technology of China, Chengdu, China), river samples were collected from different sites along the Qingshui river (Chengdu, China) and reservoir samples were collected from Zipingpu and Tuanjie reservoir (Chengdu, China). A $50 \mathrm{~mL}$ plastic syringe equipped with a $0.22 \mu \mathrm{m}$ membrane filter was used for sampling. The syringe was filled while under water to prevent headspace formation. Collected samples were stored in the dark at $\sim 4{ }^{\circ} \mathrm{C}$ in an expanded polypropylene ice cooler box until analyzed. evaluated by (pseudo)continuous monitoring to determine DMS in East Lake (University of Electronic Science and Technology of China campus, China) over a $10 \mathrm{~h}$ period (66 samples) on May 17, 2019. Samples were continuously collected at a fixed position and a depth of $50 \mathrm{~cm}$, as described in section 2.3, and introduced into the MSSF-CL system for DMS measurement (results shown in Fig. 8). The DMS concentration increased steadily from 09:00 h, reaching a maximum of $7.37 \mathrm{nM}$ at 14:00. A significant drop was then observed, decreasing to $4.06 \mathrm{nM}$ at 19:20.

The data in Figs. 7 and 8 are within the range of previous freshwater DMS observations [48]. The DMS observations follow a similar diurnal cycle that has been observed in other studies $[27,49]$. The proposed method is reagent free, portable (weight $\sim 5.1 \mathrm{~kg}$ excluding the gas cylinders), simple to use and ideally suited for field analysis with good temporal resolution.

The main attractions of the MSSF-CL system for DMS measurement, which incorporates a novel microslug gas-liquid segmented flow approach for DMS phase transfer, are that it is a fully automated measurement system that is portable, easy to operate and can be left unattended in the field for several hours to provide good temporal resolution data for investigating environmental processes.

\section{Conclusions}

DMS biogeochemistry has attracted significant attention in environmental studies as a biologically-generated, climate-relevant sulfur compound. We have developed an automated system based on gasliquid segmented flow and gas phase CL detection for the quantification of DMS in natural waters. DMS transfer from the aqueous phase to the gas phase using a vario-directional, microslug gas-liquid segmented manifold was highly advantageous compared with the commonly-used bubble purging approach. Sample throughput, including in-situ sampling, separation, detection and washing, was $6.6 \mathrm{~h}^{-1}$. The system is portable, reagent free, uses off-the-shelf components and fittings for ease of assembly/disassembly and can be deployed unattended in the field. The geometry and flow rates in the gas-liquid segmentation system are critical for optimum performance, as are the flow rate and concentration

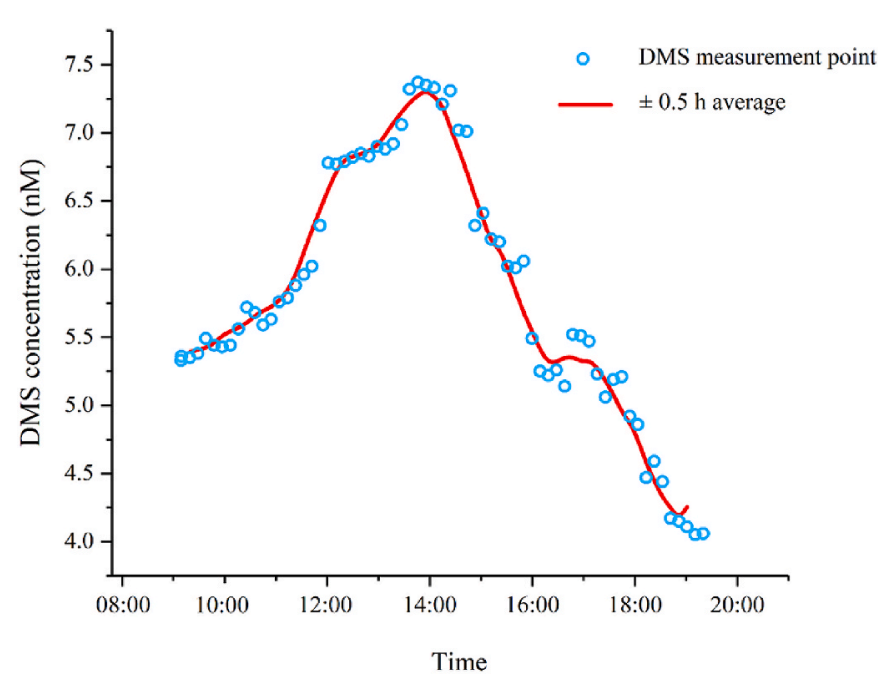

Fig. 8. Field analysis of DMS in freshwater by MSSF-CL. The MSSF-CL system was placed at a fixed position on a footbridge over the East Lake of University of Electronic Science and Technology of China campus, and samples were continuously collected from $50 \mathrm{~cm}$ below the water surface and delivered into the MSSF-CL system for analysis. DMS measurements were automatically carried out from 09:10 to 19:20 (local time) without interruption, providing DMS data every $\sim 9.1 \mathrm{~min}$. The red line is a $\pm 30 \mathrm{~min}$ running average. (For interpretation of the references to colour in this figure legend, the reader is referred to the Web version of this article.) 
of ozone in the reaction cell. Under optimum operating conditions the linear range for DMS detection was $0.05-500 \mathrm{nM}\left(\mathrm{R}^{2}=0.9984\right)$, the LOD ( $3 \times$ S/N ratio) was $0.015 \mathrm{nM}$, RSDs were typically $\leq 1.8 \%(\mathrm{n}=5)$ and recoveries for spiked (10, 20 and $50 \mathrm{nM}$ DMS) natural waters were 94.4-107.8\%. The analytical performance of the proposed method means that it can be applied to the continuous measurement of low level DMS concentrations in natural waters. Sample throughput could be enhanced by the use of a multi parallel gas-liquid segmented flow manifold and/or tangential flow filtration. The multi parallel segmented flow manifold would introduce samples into different parallel gas-liquid segmented flows at prescribed time intervals and queue the sample gas prior to entering the CL cell. In-line tangential flow filtration could be incorporated to enable longer-term deployments.

\section{Credit author statement}

Geng Leng: Conceptualization, Methodology, Formal analysis, Investigation, Writing - original draft, Writing - review \& editing, Visualization, Investigation, Resources. Chao Feng Jin: Methodology, Writing - review \& editing, Software, Visualization, Investigation. Thomas G. Bell: Writing - review \& editing, Formal analysis, Resources, Conceptualization. Simon J. Ussher: Project administration, Writing review \& editing, Formal analysis, Resources, Conceptualization. Paul J. Worsfold: Supervision, Conceptualization, Writing - review \& editing, Formal analysis, Resources. Wei-Yi Li: Validation, Writing - review \& editing, Conceptualization.

\section{Declaration of competing interest}

The authors declare that they have no known competing financial interests or personal relationships that could have appeared to influence the work reported in this paper.

\section{Acknowledgements}

This work was financially supported by the National Natural Science Foundation of China (Grant No. 21904016, 21402158), Sichuan Science and Technology Program (Grant No. 2019YFG0319) and Fundamental Research Funds for the Central Universities (Grant No. 2672018ZYGX2018J088), The "Young Scholars" program of Xihua University (21020002), The European Commission Marie Skłodowska Curie Career Integration Grant supported time and resource for SJU (PCIG-GA-2012-778 333143 DISCOSAT) and Royal Society Research Grant (Ref. No. RG140141) supported the contribution and resource for TGB.

\section{Appendix A. Supplementary data}

Supplementary data to this article can be found online at https://doi. org/10.1016/j.talanta.2020.121595.

\section{References}

[1] C.L. Lee, P. Brimblecombe, Anthropogenic contributions to global carbonyl sulfide, carbon disulfide and organosulfides fluxes, Earth Sci. Rev. 160 (2016) 1-18.

[2] A. Lana, T.G. Bell, R. Simó, S.M. Vallina, J. Ballabrera-Poy, A.J. Kettle, J. Dachs, L. Bopp, E.S. Saltzman, J. Stefels, E.S. Johnson, P.S. Liss, An updated climatology of surface dimethlysulfide concentrations and emission fluxes in the global ocean, Global Biogeochem. Cycles 25 (2011) GB1004.

[3] M. Sela-Adler, W. Said-Ahmad, O. Sivan, W. Eckert, R.P. Kiene, A. Amrani, Isotopic evidence for the origin of dimethylsulfide and dimethylsulfoniopropionate-like compounds in a warm, monomictic freshwater lake, Environ. Chem. 13 (2016) $340-351$.

[4] J.O. Nriagu, D.A. Holdway, Production and release of dimethyl sulfide from the Great Lakes, Tellus B 41 (1989) 161-169.

[5] K. Huang, G. Zhuang, J. Li, Q. Wang, Y. Sun, Y. Lin, J.S. Fu, Relation between optical and chemical properties of dust aerosol over Beijing, China, J. Geophys. Res. Atmos. 115 (2010) D00K13.
[6] H.B. Swan, E.S.M. Deschaseaux, B.D. Eyre, G.B. Jones, Surface flux and vertical profile of dimethyl sulfide in acid sulfate soils at Cudgen Lake, northern New South Wales, Australia, Chemosphere 228 (2019), 309-307.

[7] C.M. Geng, Y.J. Mu, Carbonyl sulfide and dimethyl sulfide exchange between trees and the atmosphere, Atmos. Environ. 40 (2006) 1373-1383.

[8] K.J. Sanchez, C. L Chen, L.M. Russell, R. Betha, J. Liu, D.J. Price, P. Massoli, L. D. Ziemba, E.C. Crosbie, R.H. Moore, M. Müller, S.A. Schiller, A. Wisthaler, A.K. Y. Lee, P.K. Quinn, T.S. Bates, J. Porter, T.G. Bell, E.S. Saltzman, R.D. Vaillancourt, M.J. Behrenfeld, Substantial seasonal contribution of observed biogenic sulfate particles to cloud condensation nuclei, Sci. Rep. 8 (2018) 3235.

[9] S. Twomey, The influence of pollution on the shortwave albedo of clouds, J. Atmos. Sci. 34 (1977) 1149-1152.

[10] M.O. Andreae, D. Rosenfeld, Aerosol-cloud-precipitation interactions. Part 1. The nature and sources of cloud-active aerosols, Earth Sci. Rev. 89 (2008) 13-41.

[11] S.H. Zhang, G.P. Yang, H.H. Zhang, J. Yang, Spatial variation of biogenic sulfur in the south Yellow Sea and the East China Sea during summer and its contribution to atmospheric sulfate aerosol, Sci. Total Environ. 488-489 (2014) 157-167.

[12] S.M. Turner, G. Malin, P.S. Liss, D.S. Harbour, P.M. Holligan, The seasonal variation of dimethyl sulfide and dimethylsulfoniopropionate concentrations in nearshore waters, Limnol. Oceanogr. 33 (1988) 364-375.

[13] B. Wang, E.C. Sivret, G. Parcsi, R.M. Stuetz, Determination of VOSCs in sewer headspace air using TD-GC-SCD, Talanta 137 (2015) 71-79.

[14] Y. Liu, C.Y. Liu, G.P. Yang, H.H. Zhang, S.H. Zhang, Bioindication assessment of activated sludge adaptation in a lab-scale experiment, Environ. Chem. 13 (2016) $127-139$.

[15] M.M. Zhang, L.Q. Chen, Continuous underway measurements of dimethyl sulfide in seawater by purge and trap gas chromatography coupled with pulsed flame photometric detection, Mar. Chem. 174 (2015) 67-72.

[16] H.B. Swan, R.W. Crough, P. Vaattovaara, G.B. Jones, E.S.M. Deschaseaux, B D. Eyre, B. Miljevic, Z.D. Ristovski, Dimethyl sulfide and other biogenic volatile organic compound emissions from branching coral and reef seawater: potential sources of secondary aerosol over the Great Barrier Reef, J. Atmos. Chem. 73 (2016) 303-328.

[17] T.G. Bell, G. Malin, G.A. Lee, J. Stefels, S. Archer, M. Steinke, P. Matrai, Special issue of the 5 th international symposium on biological and environmental chemistry of DMS(P) and related compounds, Biogeochemistry 110 (2012) 147-161. Goa, India, 19-22 October 2010, Global oceanic DMS data intercomparability.

[18] C.F. Walker, M.J. Harvey, M.J. Smith, T.G. Bell, E.S. Saltzman, A.S. Marriner, J. A. McGregor, C.S. Law, Assessing the potential for dimethylsulfide enrichment at the sea surface and its influence on air-sea flux, Ocean Sci. 12 (2016) 1033-1048.

[19] P.D. Tortell, Dissolved gas measurements in oceanic waters made by membrane inlet mass spectrometry, Limnol Oceanogr. Methods 3 (2005) 24-37.

[20] S. Kameyama, H. Tanimoto, H. Inomata, U. Tsunogai, A. Ooki, Y. Yokouchi, S. Takeda, H. Obata, M. Uematsu, Equilibrator inlet-proton transfer reaction-mass spectrometry (EI-PTR-MS) for sensitive, high-resolution measurement of dimethyl sulfide dissolved in seawater, Anal. Chem. 81 (2009) 9021-9026.

[21] S. Kameyama, S. Yoshida, H. Tanimoto, S. Inomata, K. Suzuki, H. YoshikawaInoue, High-resolution observations of dissolved isoprene in surface seawater in the Southern Ocean during austral summer 2010-2011, J. Oceanogr. 70 (2014) 225-239.

[22] H. Tanimoto, S. Kameyama, T. Iwata, S. Inomata, Y. Omori, Measurement of air-sea exchange of dimethyl sulfide and acetone by PTR-MS coupled with gradient flux technique, Environ. Sci. Technol. 48 (2014) 26-533.

[23] J.C. Jiang, Y. Wang, K.Y. Hou, L. Hua, P. Chen, W. Liu, Y.Y. Xie, H.Y. Liu, Photoionization-generated dibromomethane cation chemical ionization source for TOFMS and its application on sensitive detection of volatile sulfur compounds, Anal. Chem. 88 (2016) 5028-5032.

[24] E.S. Saltzman, W.J. De Bruyn, M.J. Lawler, C.A. Marandino, C.A. McCormick, A chemical ionization mass spectrometer for continuous underway shipboard analysis of dimethylsulfide in near-surface seawater, Ocean Sci. 5 (2009) 537-546.

[25] T.J. Kelly, J.S. Gaffney, M.F. Phillips, R.L. Tanner, Chemiluminescent detection of reduced sulfur compounds with ozone, Anal. Chem. 55 (1983) 135-138.

[26] P.K. Arora, J.P.S. Chatha, Chemiluminescence from the reactions of ozone with sulphur compounds, Can. J. Chem. 62 (1984) 417-423.

[27] B.C. Green, D.J. Suggett, A. Hills, M. Steinke, Optimisation of a fast DMS sensor (FDS) for real time quantification of dimethyl sulfide production by algae, Biogeochemistry 110 (2012) 163-172.

[28] K. Toda, P.K. Dasgupta, New applications of chemiluminescence for selective gas analysis, Chem. Eng. Commun. 195 (2008) 82-97.

[29] M.A.K. Azad, S. Ohira, K. Toda, Single column trapping/separation and chemiluminescence detection for on-site measurement of methyl mercaptan and dimethyl sulfide, Anal. Chem. 78 (2006) 6252-6259.

[30] D. Okane, E.P. Koveke, K. Tashima, K. Saeki, S. Maezono, T. Nagahata, N. Hayashi, K. Owen, D.P. Zitterbart, S. Ohira, K. Toda, High sensitivity monitoring device for onboard measurement of dimethyl sulfide and dimethylsulfoniopropionate in seawater and an oceanic atmosphere, Anal. Chem. 91 (2019) 10484-10491.

[31] N. Takanori, H. Kajiwara, S.I. Ohira, K. Toda, Simple field device for measurement of dimethyl sulfide and dimethylsulfoniopropionate in natural waters, based on vapor generation and chemiluminescence detection, Anal. Chem. 85 (2013) 4461-4467.

[32] M. Donata, S.W. Fries, R.V.R. Philipp, Gas-liquid two-phase flow in meandering microchannels, Chem. Eng. J. 135S (2008) S37-S45.

[33] D. Hakan, N. Selman, M. Metin, Mixing of miscible liquids in gas-segmented serpentine channels, Int. J. Multiphas. Flow 35 (2009) 1149-1158. 
[34] J. Tan, Y.C. Lu, J.H. Xu, G.S. Luo, Mass transfer performance of gas-liquid segmented flow in microchannels, Chem. Eng. J. 181-182 (2012) 229-235.

[35] J. Stafford, Principle-based design of distributed multiphase segmented flow, Int. J. Heat Mass Tran. 100 (2016) 508-521.

[36] P. Garstecki, M.J. Fuerstman, H.A. Stone, G.M. Whitesides, Formation of droplets and bubbles in a microfluidic T-junction-scaling and mechanism of break-up, Lab Chip 6 (2006), 693-693.

[37] T. Thorsen, R.W. Roberts, F.H. Arnold, S.R. Quake, Dynamic pattern formation in a vesicle-generating microfluidic device, Phys. Rev, Lett. 86 (2001) 4163-4166.

[38] J.D. Tice, A.D. Lyon, R.F. Ismagilov, Effects of viscosity on droplet formation and mixing in microfluidic channels, Anal. Chim. Acta 507 (2004) 73-77.

[39] B. Kolb, L.S. Ettre, Static Headspace-Gas Chromatography: Theory and Practice, 2 ed., 2006. Proteomics.

[40] W.A. Kummer, J.N. Pitts, R.P. Steer, Intraoperative ultrasonic localization of endocrine tumors of the pancreas, Environ. Sci. Technol. 5 (1971) 1045-1047.

[41] S. Ohira, J. Li, W.A. Lonneman, P.K. Dasgupta, K. Toda, Can breath isoprene be measured by ozone chemiluminescence, Anal. Chem. 79 (2007) 2641-2649.

[42] D.A. Exton, D.J. Smith, T.J. McGenity, M. Steinke, A.J. Hills, D.J. Suggett, Application of a fast isoprene sensor (FIS) for measuring isoprene production from marine samples, Limnol Oceanogr. Methods 8 (2010) 185-195.
[43] S. Schulze, D. Zahn, R. Montes, R. Rodil, J.B. Quintana, T.P. Knepper, T. Reemtsma, U. Berger, Occurrence of emerging persistent and mobile organic contaminants in European water samples, Water Res. 153 (2019) 80-90.

[44] D. Tanzer, K.G. Heumann, Gas Chromatographic Trace-level determination of volatile organic sulfides and selenides and of methyl iodide in atlantic surface water, Int. J. Environ. Anal. Chem. 48 (1) (1992) 17-31.

[45] P.R. Berube, P.D. Parkinson, E.R. Hall, Measurement of reduced sulphur compounds contained in aqueous matrices by direct injection into a gas chromatograph with a flame photometric detector, J. Chromatogr., A 830 (1999) $485-489$.

[46] M.E. Hines, R.E. Pelletier, P.M. Crill, Emissions of sulfur gases from marine and freshwater wetlands of the Florida Everglades: rates and extrapolation using remote sensing, J. Geophys. Res. 98 (1993) 8991-8999.

[47] J. Sun, S. Hu, K.R. Sharma, B. Kellerlehmann, Z. Yuan, An efficient method for measuring dissolved VOSCs in wastewater using GC-SCD with static headspace technique, Water Res. 52 (2014) 208-217.

[48] B.K. Reese, M.A. Anderson, Dimethyl sulfide production in a saline eutrophic lake, Salton Sea, California, Limnol. Oceanogr. 54 (1) (2009) 250-261.

[49] S.J. Royer, M. Galí, A.S. Mahajan, O.N. Ross, G.L. Pérez, E.S. Saltzman, R. Simó, A high-resolution time-depth view of dimethylsulphide cycling in the surface sea, Sci. Rep. 6 (2016) 32325. 